\title{
Uncertainty Due to Pandemic and the Volatility Connectedness Among Asian REITs Market
}

\author{
Ololade Periola-Fatunsin ${ }^{1}$, , Johnson A. Oliyide ${ }^{2}$, Ismail O. Fasanya ${ }^{3}$ (D) \\ 1 Research Department, DAWN Commission, Cocoa House, 10th Floor, Building, Ibadan, Nigeria, 2 Department of Economics, Federal University of \\ Agriculture, Abeokuta, Nigeria, ${ }^{3}$ School of Economics and Finance, University of the Witwatersrand, Johannesburg, South Africa \\ Keywords: covid-19, volatility connectedness, asian reits market, uncertainty
}

https://doi.org/10.46557/001c.22323

\section{Asian Economics Letters}

Vol. 2, Issue 2, 2021

With increasing COVID-19 cases and instability of many financial markets, we examine the role of uncertainty due to infectious diseases in influencing volatility connectedness among Asian Real Estate Investment Trust market. Our result unveils the importance of uncertainty due to pandemic in driving the connectedness among the markets in both the mean and variance. These results carry implications for hedging and portfolio diversification for financial participants.

\section{Introduction}

In this paper, we examine the causal influence of uncertainty due to pandemic on the volatility transmission among the Asian-Pacific Real Estate Investment Trust (hereafter, REITs) markets. In this vein, we motivate our study in three ways. First, the COVID-19 pandemic, which has its origin from the Asian-Pacific region (Akinsomi, 2020), has been noted as having a significant influence on the global REITs market (Akinsomi, 2020), and other financial markets, causing them to be volatile and subtle to shocks (Adekoya \& Oliyide, 2020; Iyke, 2020a, 2020b). Second, Liow \& Huang (2018) document that the volatility transmission between international REITs' is sensitive to crises. With this, a market can transmit shocks or volatility to another market due to the increasing integration of these markets (Adekoya \& Oliyide, 2020). Third, just like other forms of uncertainty, the uncertainty due to pandemic raises fear and sentiments among investors and other economic agents (Fasanya et al., 2021; Iyke \& Ho, 2021), thus, accounting for the risk-receiving and -giving characteristics of markets will provide insights into hedging possibilities and portfolio diversification.

Undoubtedly, several studies have noted the possible connection among REITs markets of different countries. Ngene et al. (2020), for instance, unveil the presence of time-varying efficiency of the REITs markets. Hestiawan \& Prijadi (2020) reveal the presence of low return connectedness among the Asian REITs market. Liow \& Huang (2018) document that the connectedness between international REITs market is sensitive to crises. In fact, their study further documents that investors should pay close attention to uncertainty due to economic policy and interest rate move- ment.

This study contributes to the literature in two ways. First, we examine the dynamic connectedness among the Asian-Pacific REITs using the time-varying parameter vector autoregressive (VAR) model of Antonakakis et al. (2020). Second, we suspect that the increased transmission among the Asian REITs market, as noted in Section II.B, might be due to the current COVID-19. As a result, we follow the recent trend, as in Fasanya et al. (2021), to examine the causal influence of uncertainty induced by the pandemic on the connectedness measures of the Asian REITs using linear and nonlinear models.

The rest of the paper is structured as follows. Section II discusses the data metrics and the methodology used, while Sections III and IV, respectively, discuss results and conclude the study.

\section{Data and Methodology}

\section{A. Data}

We sourced data for the REITs markets of the six Asian countries and Infectious Diseases Equity Market Volatility (hereafter, EMVID). The former is obtained from DataStream, while the latter is sourced from www.policyuncertainty.com. Due to the objective of the study, we utilize daily frequency data which ranges from $1 / 1 / 2020$ to $31 / 12$ / 2020. For the connectedness approach, we first generate the returns series ${ }^{1}$ which is computed as the log differences of the prices measured in percentage form. We then utilize the volatility series, which was derived through a GARCH $(1,1)$ process, for the spillover analysis.

\footnotetext{
a Corresponding Author Email: ololade.fatunsin@dawncommission.org

1 Since prices were non-stationary, based on standard unit root tests, we work with returns. Complete details of the unit root tests are available upon request from the authors.
} 


\section{B. Methodology}

The empirical analysis is structured into two parts. In the first part, we examine the volatility connectedness between the Asian REITs markets by using the time-varying parameter vector autoregressive (TVP-VAR) model while the second part examines the causal effects of uncertainty due to infectious diseases on the market dynamics via various linear and non-linear causality tests.

Following Antonakakis et al. (2020), we calculate the generalized impulse response functions (GIRF) and generalized forecast error variance decompositions (GFEVD), which are crucial in estimating the dynamic connectedness, as follows:

$$
\tilde{\rho}_{i j, t}(H)=\frac{\sum_{t=1}^{H-1} \alpha_{i j, t}^{2}}{\sum_{j=1}^{m} \sum_{t=1}^{H-1} \alpha_{i j, t}^{2}}
$$

where $\sum_{j=1}^{n} \tilde{\rho}_{i j, t}(H)=1$ and $\sum_{i, j=1}^{n} \tilde{\rho}_{i j, t}(H)=m$

In Equation (1), the numerator is the cumulative effect of a shock in variable $i$, while the denominator is the cumulative effect of all shocks. Following this, we deduce the total connectedness index using the following GFEVD:

$$
\begin{aligned}
C_{t}(H) & =\frac{\sum_{i, j=1, i \neq j}^{m} \tilde{\rho}_{i j, t}(H)}{\sum_{i, j=1}^{m} \tilde{\rho}_{i j, t}(H)} * 100 \\
& =\frac{\sum_{i, j=1, i \neq j}^{m} \tilde{\rho}_{i j, t}(H)}{m} * 100
\end{aligned}
$$

In the next step, we follow the Balcilar et al. (2016) methodology that extends the frameworks of Nishiyama et al. (2011) and Jeong et al. (2012) by developing a test for the second moment in order to detect nonlinear causality. In short, they adopt the nonparametric Granger-quantilecausality approach of Nishiyama et al. (2011). To illustrate the causality in higher order moment, they assume:

$$
y_{t}=h\left(V_{t-1}\right)+\vartheta\left(U_{t-1}\right) \tau_{t},
$$

where $\tau_{t}$ is the white noise process and $h(\cdot)$ and $\vartheta(\cdot)$ equal the unknow functions that satisfy pertinent conditions for stationarity. Although, this specification allows non granger-type causality testing from $U_{t-1}$ to $y_{t}$, it can detect the "predictive power" from $U_{t-1}$ to $y_{t}^{2}$ when $\vartheta(\cdot)$ is a general nonlinear function. Thus, Equation (3) is re-formulated to account for the null and alternative hypothesis for causality in variance in Equations (4) and (5), respectively.

$$
\begin{aligned}
& H_{0}=P\left\{F_{y_{t}^{2} \mid W_{t-1}}\left\{Q_{\sigma}\left(y_{t} \mid W_{t-1}\right)\right\}=\sigma\right\}=1, \\
& H_{1}=P\left\{F_{y_{t}^{2} \mid W_{t-1}}\left\{Q_{\sigma}\left(y_{t} \mid W_{t-1}\right)\right\}=\sigma\right\}<1,
\end{aligned}
$$

We obtain the feasible test statistic for testing the null hypothesis in Equation (6). Following Jeong et al. (2012), Balcilar et al. (2016) overcome the issue that causality in mean implies causality in variance. Specifically, they interpret the causality in higher-order moments through the use of the following model:

$$
y_{t}=h\left(U_{t-1}, V_{t-1}\right)+\tau_{t},
$$

Thus, the higher order quantile causality is given as:

$$
\begin{array}{r}
H_{0}=P\left\{F_{y_{t}^{k} \mid W_{t-1}}\left\{Q_{\sigma}\left(y_{t} \mid W_{t-1}\right)\right\}=\sigma\right\}=1, \\
\text { for } k=1,2, \ldots, k, \\
H_{1}=P\left\{F_{y_{t}^{k} \mid W_{t-1}}\left\{Q_{\sigma}\left(y_{t} \mid W_{t-1}\right)\right\}=\sigma\right\}<1, \\
\text { for } k=1,2, \ldots, k .
\end{array}
$$

Overall, we test that $x_{t}$ Granger causes $y_{t}$ in $\sigma t h$ quantile up to the $K$-th moment through the use of Equation (7) to construct the test statistic of the equation of the first moment for each $k$.

\section{Result Presentation and Discussion}

\section{A. Preliminary Result}

The influence of the COVID-19 pandemic is unveiled in the average values of REITs of all the countries and the EMVID as presented in the descriptive statistics table (see Table 1, Panel A). Except for Turkey (whose average value is relatively low), other countries have negative returns on average, while the infectious diseases show a high average number. The standard deviation statistics further reveal the likelihood of fluctuations in all the series with that of the EMVID having the greatest fluctuations. The skewness, kurtosis and Jaque-Bera statistics reveal that all the series are non-normal. On the other hand, the stationary tests reveal that all the series are stationary at level.

\section{B. Spillover Results}

Following the first objective of this study, we present the spillover results in Panel B of Table 1. For ease of interpretation: a market is said to be a net receiver of shocks if the value is less than zero, and a net transmitter of shocks if the value is greater than zero. As unveiled in Panel B results, China, Hong Kong, Malaysia and Turkey are net receivers of spillovers, while Japan and Singapore are net transmitters of shocks. These findings corroborate those of Pham (2012), who noted the possibility of transmission from Japan and Singapore to other emerging markets during the crisis period (in his case, the 2007-2009 global financial crisis). Intuitively, the market which is categorized as net receiver of volatility spillovers can suitably hedge against risk in other markets

Unlike the study of Hestiawan \& Prijadi (2020), which documented a relatively low total connectedness index of 14.08\% among Asian REITs, our study through the TVPVAR model finds a high connectedness of $55.5 \%$ among the Asian REITs market. We suspect that the huge difference is due to our focus on the period of the COVID-19 pandemic.

\section{Causality Tests}

In the previous section, we document the presence of high connectedness among the Asian REITs market. We proceed further in this section to analyse the causal influence of infectious diseases on the total spillover and net directional connectedness of the REITs market. We start by documenting the evidence of linear causality from EMVID to the connectedness measure using the Granger causality test. As documented in Table 1 (Panel B), EMVID causes all the connectedness measures except the net directional connectedness of China and Hong Kong. Nevertheless, we cannot rely on the result of the linear causality test due to the possibility of poor performance in the presence of undesirable statistical properties and nonlinearities (see, Adekoya \& Oliyide, 2020; Balcilar et al., 2016; Fasanya et al., 2021). With this in mind, we proceed to performing the Brook et al (BDS test, 1996), which can unveil the presence of nonlin- 
Table 1: Descriptive statistics and dynamic connectedness results

\begin{tabular}{|c|c|c|c|c|c|c|c|}
\hline \multicolumn{8}{|c|}{ Panel A: Descriptive statistics } \\
\hline & China & Hong Kong & Japan & Malaysia & Singapore & Turkey & EMVID \\
\hline Mean & -0.076 & -0.063 & -0.049 & -0.034 & -0.025 & 0.051 & 19.652 \\
\hline Maximum & 7.839 & 6.229 & 12.923 & 3.539 & 8.659 & 9.178 & 68.370 \\
\hline Minimum & -6.983 & -10.124 & -21.826 & -6.907 & -10.840 & -13.981 & 0.000 \\
\hline Std. Dev. & 1.881 & 1.662 & 2.556 & 1.002 & 2.025 & 3.029 & 13.283 \\
\hline Skewness & 0.196 & -0.426 & -1.817 & -1.459 & -0.710 & -0.450 & 0.990 \\
\hline Kurtosis & 6.205 & 9.018 & 29.966 & 13.331 & 10.377 & 5.592 & 4.273 \\
\hline Jarque-Bera & $113.36^{* * *}$ & $401.72^{* * *}$ & $8051.4^{* * *}$ & $1253.2^{* * *}$ & $613.6^{* * *}$ & $81.87^{* * *}$ & $60.24^{* * *}$ \\
\hline PP unit root test & $16.28^{* * *}$ & $13.03^{* * *}$ & $-9.92^{* * *}$ & $13.27^{* * *}$ & $-13.61^{* * *}$ & $15.41^{* * *}$ & $-5.63^{* * *}$ \\
\hline \multicolumn{8}{|c|}{ Panel B: Dynamic connectedness results } \\
\hline & China & Hong Kong & Japan & Malaysia & Singapore & Turkey & FROM \\
\hline China & 32.1 & 1.9 & 24.5 & 14.9 & 21.7 & 4.9 & 67.9 \\
\hline Hong Kong & 7.7 & 50.5 & 14 & 7.6 & 15.9 & 4.3 & 49.5 \\
\hline Japan & 14.7 & 3.2 & 48.6 & 4.9 & 24.2 & 4.4 & 51.4 \\
\hline Malaysia & 5.4 & 1.5 & 18.4 & 38.5 & 27.6 & 8.5 & 61.5 \\
\hline Singapore & 11.7 & 3.7 & 32.9 & 12 & 32.7 & 7 & 67.3 \\
\hline Turkey & 11.3 & 1 & 9.4 & 5.2 & 8.4 & 64.6 & 35.4 \\
\hline TO others & 50.8 & 11.3 & 99.3 & 44.7 & 97.8 & 29.1 & 332.9 \\
\hline NET & -17 & -38.3 & 47.9 & -16.8 & 30.6 & -6.3 & $\mathrm{TCl}=55.5$ \\
\hline \multicolumn{8}{|c|}{ Panel C: BDS test results } \\
\hline Variables & & 2 & 3 & 4 & 5 & 6 & \\
\hline Total spillover & & $0.080^{* * *}$ & $0.147^{* * *}$ & $0.188^{* * *}$ & $0.209^{* * *}$ & $0.218^{* * *}$ & \\
\hline Net China & & $0.063^{* * *}$ & $0.121^{* * *}$ & $0.155^{* * *}$ & $0.173^{* * *}$ & $0.179^{* * *}$ & \\
\hline Net Hong Kong & & 0 & $0.008^{* * *}$ & $0.015^{* * *}$ & $0.023^{* * *}$ & $0.030^{* * *}$ & \\
\hline Net Japan & & $0.096^{* * *}$ & $0.171^{* * *}$ & $0.216^{* * *}$ & $0.236^{* * *}$ & $0.243^{* * *}$ & \\
\hline Net Malaysia & & $0.067^{* * *}$ & $0.119^{* * *}$ & $0.150^{* * *}$ & $0.160^{* * *}$ & $0.157^{* * *}$ & \\
\hline Net Singapore & & $0.081^{* * *}$ & $0.140^{* * *}$ & $0.177^{* * *}$ & $0.191^{* * *}$ & $0.204^{* * *}$ & \\
\hline Net Turkey & & $0.021^{* * *}$ & $0.037^{* * *}$ & $0.048^{* * *}$ & $0.051^{* * *}$ & $0.049^{* * *}$ & \\
\hline
\end{tabular}

This table has results divided into three parts. Panel A has descriptive statistics, Panel B has connectedness results, and Panel C has the BDS test (values reported are the $p$-value of the BDS test statistic). The symbols **** represents statistical significance at the $1 \%$ level. Results in Panel B are based on TVP-VAR(2) and a 10-step-ahead generalized forecast error variance decomposition.

earities among the series.

As reported in Table 1 (Panel C), there is the presence of non-linearity among the series. We, therefore, proceed to the non-parametric causality test (represented by Figure 1), which can reveal causality in both the mean and variance. As shown in Figure 1, the connectedness measures are driven by COVID-19 in almost all the quantiles for the causality in the mean. In relation to the causality in the variance, COVID-19 also causes the significant fluctuations in net connectedness of all the countries' REITS. While it is more prominent around the middle quantiles for Malaysia and Singapore, it does not cause the fluctuations in the total spillover. In all, our results highlight: (a) the importance of accounting for nonlinearity when testing for the role of EMVID in predicting Asian REITs returns; and (b) that the period of the recent global pandemic tends to be a strong predictor for the Asian REITs, especially when the market is operating in a normal mode.

\section{Conclusion}

In this study, we have two objectives. The first is to examine the connectedness among Asian REITs market. The second is to examine the causal influence of uncertainty due to pandemic on the connectedness measures of the Asian REITs market. To meet these objectives, we utilize the TVPVAR model and the nonparametric causality-in-quantiles technique. Our main finding is that there is a high connectedness among the Asian REITs market during the COVID-19 pandemic period with the REITs markets of Japan and Singapore being net transmitters of volatility spillovers. We further uncover that uncertainty due to infectious diseases significantly drives all the connectedness measures in mean, while it tracks all the connectedness measures in variance, expect for the total spillover. Our conclusion complements the evidence of the significant influence of infectious diseases on the functioning of financial markets. While accounting for the role of nonlinearity, upcoming 
Causality in mean

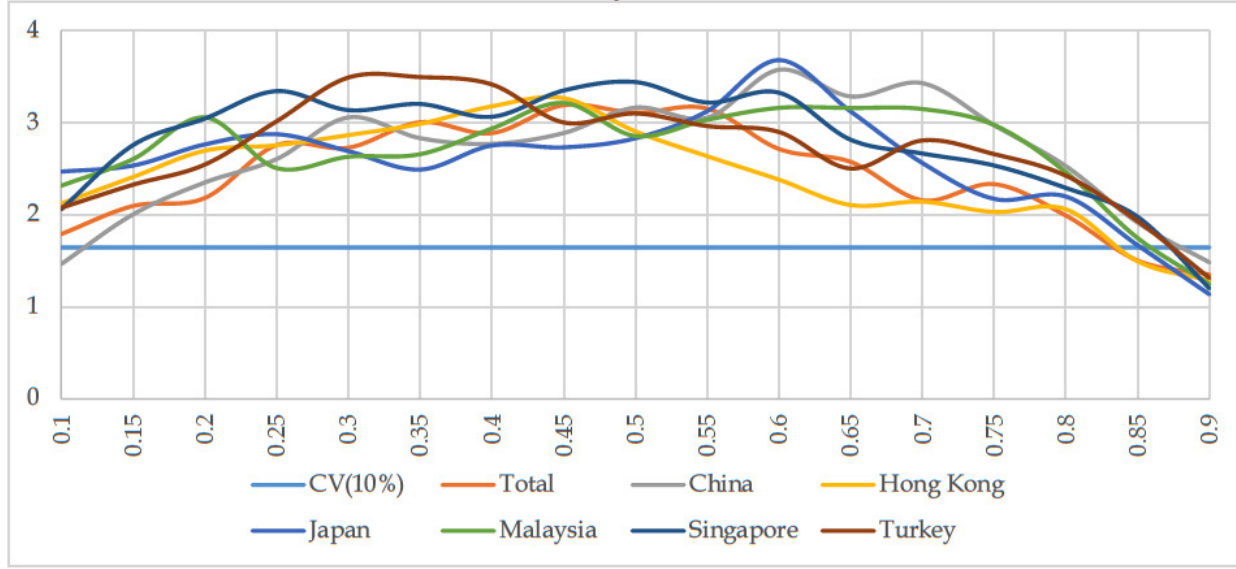

Causality in variance

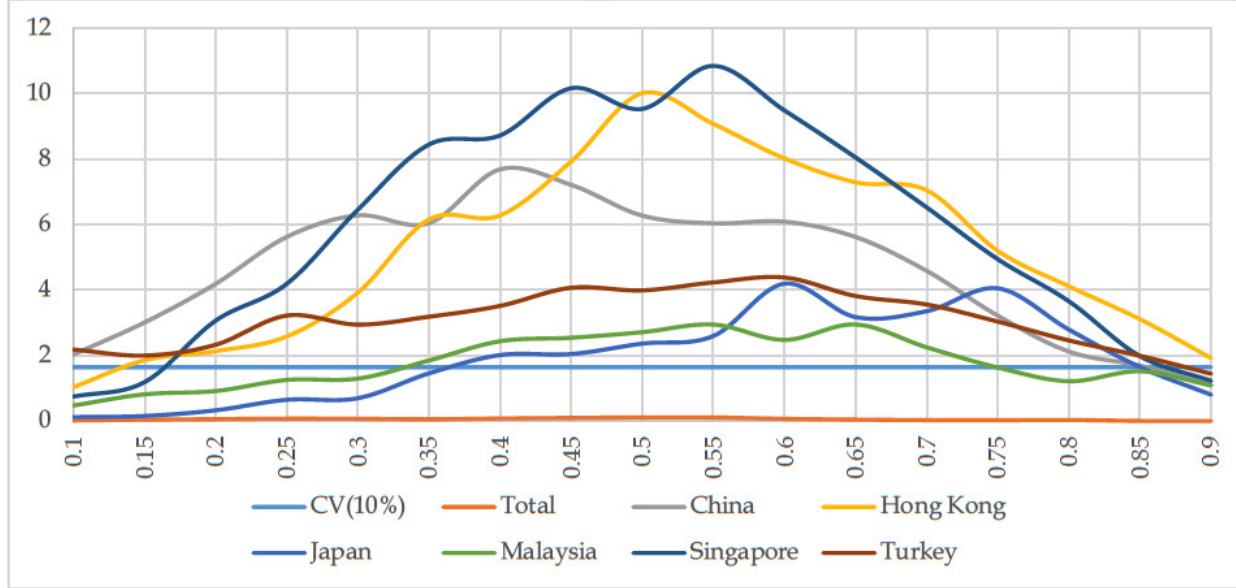

\section{Figure 1: Causality in mean and variance}

This figure plots the result of the causal influence of EMVID on the derived spillover measures through the non-parametric causality test of Balcilar et al. (2016). The Y-axis reports the test statistic, while the $\mathrm{X}$-axis reports the quantiles. The decision of significance as noted by the $\mathrm{CV}(10 \%)$ is hedged on $10 \%(1.645)$.

studies can also look at the influence of uncertainty due to the pandemic or economic policies on the connectedness among the US and Asian REITs market.
Submitted: January 30, 2021 AEST, Accepted: April 07, 2021

AEST 


\section{REFERENCES}

Adekoya, O. B., \& Oliyide, J. A. (2020). How COVID-19 drives connectedness among commodity and financial markets: Evidence from TVP-VAR and causality-in-quantiles techniques. Resources Policy, 70, 101898. https://doi.org/10.1016/i.resourpol.2020.1 $\underline{01898}$

Akinsomi, O. (2020). How resilient are REITs to a pandemic? The COVID-19 effect. Journal of Property Investment \& Finance, 39(1), 19-24. https://doi.org/1 0.1108/jpif-06-2020-0065

Antonakakis, N., Chatziantoniou, I., \& Gabaur, D. (2020). Redefined measures of dynamic Connectedness based on time-varying parameter vector autoregressions. J Risk Financ Manag, 13(84).

Balcilar, M., Gupta, R., Kim, W. J., Kyei, C., \& Wohar, M. E. (2016). Does economic policy uncertainty predict exchange rate returns and volatility? Evidence form a nonparametric causality-in-quantiles Test. Open Economics Review, 27(2), 229-250. https://doi.or $\mathrm{g} / 10.1007 / \mathrm{s} 11079-016-9388-\mathrm{x}$

Broock, W. A., Dechert, W. D., Scheinkman, J. A., \& LeBaron, B. (1996). A test for independence based on the correlation dimension. Econometric Reviews, 15(3), 197-235. https://doi.org/10.1080/0747493960880035 3

Fasanya, I., Oyewole, O., \& Odei-Mensah, J. (2021). Infectious Diseases-Energy Futures Nexus: A Quantile-on-Quantile Approach. Energy Research Letters, 1(4). https://doi.org/10.46557/001c.18267

Hestiawan, L., \& Prijadi, R. (2020). Return spillover of Asian REITs. Indonesian Capital Market Review, 12, 93-106.
Iyke, B. N. (2020a). The disease outbreak channel of exchange rate return predictability: Evidence from COVID-19. Emerging Markets Finance and Trade, 56(10), 2277-2297. https://doi.org/10.1080/1540496 $\underline{\mathrm{x} .2020 .1784718}$

Iyke, B. N. (2020b). Economic Policy Uncertainty in Times of COVID-19 Pandemic. Asian Economics Letters, 1(2). https://doi.org/10.46557/001c.17665

Iyke, B. N., \& Ho, S.-Y. (2021). Investor attention on COVID-19 and African stock returns. MethodsX, 8 , 101195. https://doi.org/10.1016/j.mex.2020.101195

Jeong, K., Härdle, W. K., \& Song, S. (2012). A consistent nonparametric test for causality in quantile. Econometric Theory, 28(4), 861-887. http s://doi.org/10.1017/s0266466611000685

Liow, K. H., \& Huang, Y. (2018). The dynamics of volatility connectedness in international real estate investment trusts. Journal of International Financial Markets, Institutions and Money, 55, 195-210. http s://doi.org/10.1016/j.intfin.2018.02.003

Ngene, G. M., Manohar, C. A., \& Julio, I. F. (2020). Overreaction in the REITs markets: New evidence from Quantile Autoregression Approach. Journal of Risk and Financial Management, 13(11), 282. https://d oi.org/10.3390/jrfm13110282

Nishiyama, Y., Hitomi, K., Kawasaki, Y., \& Jeong, K. (2011). A consistent nonparametric test for nonlinear causality-Specification in time series regression. Journal of Econometrics, 165(1), 112-127. https://doi.o rg/10.1016/i.jeconom.2011.05.010

Pham, A. K. (2012). The dynamics of returns and volatility in the emerging and developed Asian REIT markets. Journal of Real Estate Literature, 20(1), 79-96. https://doi.org/10.1080/10835547.2012.120903 $\underline{18}$ 